\title{
Enhanced depth imaging optical coherence tomography of choroidal osteoma with secondary neovascular membranes: report of two cases
}

\author{
Tomografia de coerência óptica com imagem profunda aprimorada de osteoma de coroide com \\ membrana neovascular secundária: relato de 2 casos
}

Patrícia Correa de Melloํ․ Patricia Berensztejn², Oswaldo Ferreira Moura Brasil ${ }^{2}$

\begin{abstract}
We report enhanced depth imaging optical coherence tomography (EDI-OCT) features based on clinical and imaging data from two newly diagnosed cases of choroidal osteoma presenting with recent visual loss secondary to choroidal neovascular membranes. The features described in the two cases, compression of the choriocapillaris and disorganization of the medium and large vessel layers, are consistent with those of previous reports. We noticed a sponge-like pattern previously reported, but it was subtle. Both lesions had multiple intralesional layers and a typical intrinsic transparency with visibility of the sclerochoroidal junction.

Keywords: Osteoma; Tomography, optical coherence; Choroidal neovascularization; Choroid neoplasms
\end{abstract}

\section{RESUMO}

Relatamos as características na tomografia computadorizada óptica (EDI-OCT) de 2 pacientes recém diagnosticados com osteoma de coroide apresentando perda visual secundária à membranas neovasculares coroideanas. As características descritas em nossos 2 casos foram consistentes com trabalhos anteriores, exibindo a compressão da coriocapilar e desorganização das camadas médias e de grandes vasos. Notamos também o padrão em esponja anteriormente descrito, porém de forma discreta. Ambas as lesões tinham várias camadas intralesionais e uma transparência intrínseca típica com visibilidade da junção da esclero-coroideana.

Descritores: Osteoma; Tomografia de coerência óptica; Neovascularização de coroide; Neoplasias da coroide

\section{INTRODUCTION}

Optical coherence tomography (OCT) plays an instrumental role in the diagnosis and follow-up of several retinal and choroidal diseases such as macular degeneration, vascular occlusion, and inflammation. Recently, OCT studies of intraocular tumors evaluated the intrinsic optical characteristics of choroidal tumors imaged using enhanced depth imaging OCT (EDI-OCT) $)^{(1)}$.

Among body structures, the choroid has one of the highest metabolic rates and supplies oxygen to the photoreceptor layer of the retina, which is also a highly metabolic structure(2). However, the choroid is one of the most difficult structures to image in vivo because pigments in the retinal pigment epithelium (RPE) and choroid impede image capturing.

EDI-OCT provides a more detailed view than spectral-domain OCT (SD-OCT) of deep anatomic structures ${ }^{(3)}$. The current axial resoIution with EDI-OCT is approximately 3.9 micra $^{(4)}$. Recently, several papers have been published describing the aspects of choroidal tumors revealed with this new technology ${ }^{(4-6)}$. With this technology, various choroidal tumors can be imaged and measured. Using EDI-OCT, choroidal nevi and melanomas show a smooth, dome-shaped surface, whereas choroidal metastases display a "lumpy-bumpy," irregular surface topography and choroidal hemangiomas present a smooth, acutely dome-shaped surface; choroidal lymphomas show a "placid," rippled, or "seasick" surface ${ }^{(4)}$.

Choroidal osteomas are rare, benign, and usually unilateral intraocular tumors composed of mature bone affecting the choroid. These tumors can be asymptomatic or can produce visual loss because of choroidal neovascularization (CNV) or tumor decalcification, presence of subretinal fluid, and photoreceptor atrophy ${ }^{(7)}$.

CNV is an important cause of vision loss in patients with choroidal osteoma and is reported to occur in 31\% of affected eyes by 10 years after the diagnosis ${ }^{(8)}$.

In this study, we evaluated the EDI-OCT features of two cases of choroidal osteoma with neovascular membranes.

\section{CASE REPORTS}

\section{CASe 1}

A 24-year-old Caucasian male experienced a sudden vision loss in his left eye. His best corrected visual acuity was 20/20 in the right eye and 20/40 in the left eye. His anterior segment examination was normal. The fundus examination revealed a choroidal osteoma involving the macular area and upper temporal vascular arcade with subretinal hemorrhage and subretinal fluid in the fovea (Figure 1).

\section{CASE 2}

A 26-year-old Caucasian female experienced a sudden vision loss in her left eye. Her best corrected visual acuity was 20/20 in the right eye and 20/40 in the left eye. Her anterior segment examination was unremarkable. The fundus examination revealed a choroidal osteoma involving the entire macular area with subretinal hemorrhage and subretinal fluid in the fovea (Figure 2).
Submitted for publication: January 14, 2015

Accepted for publication: June 23, 2015

${ }^{1}$ Setor de Retina e Tumores do Instituto Brasileiro de Oftalmologia (IBOL) e Serviço de Oftalmologia. Hospital Federal dos Servidores do Estado do Rio de Janeiro, Rio de Janeiro, RJ, Brazil.

2 Setor de Retina e Vítreo do Instituto Brasileiro de Oftalmologia (IBOL), Rio de Janeiro, RJ, Brazil.
Funding: No specific financial support was available for this study

Disclosure of potential conflicts of interest: None of the authors have any potential conflict of interest to disclose.

Corresponding author: Patrícia C. de Mello. Praia de Botafogo, 206 - Rio de Janeiro - RJ - Brazil E-mail: paticma@gmail.com 
Both patients were evaluated with SD-OCT including EDI-OCT using Cirrus Carl Zeiss OCT, fluorescein angiography, and ultrasonography.

\section{DISCUSSION}

In both cases, the lesion had a yellow-white coloration with finger-like projections and pigmentary changes in the overlying RPE. The lesions were minimally elevated $(<1.2 \mathrm{~mm})$ and hyperreflective on ultrasonography, and both cases showed small areas of decalcification. Fluorescein angiography showed early patchy hyperfluorescence and late staining, and the choroidal neovascular membranes were found in the decalcified areas in both cases. We observed an angiographic leakage in the area of the membrane. On SD-OCT, the neovascular membrane was superior to the fovea and nasal to the fovea in cases 1 and 2, respectively; both cases had the presence of subretinal fluid.

On analyzing the EDI-OCT images (Figures 3 and 4), both cases had normal inner retinal features, and the outer retina showed inte-

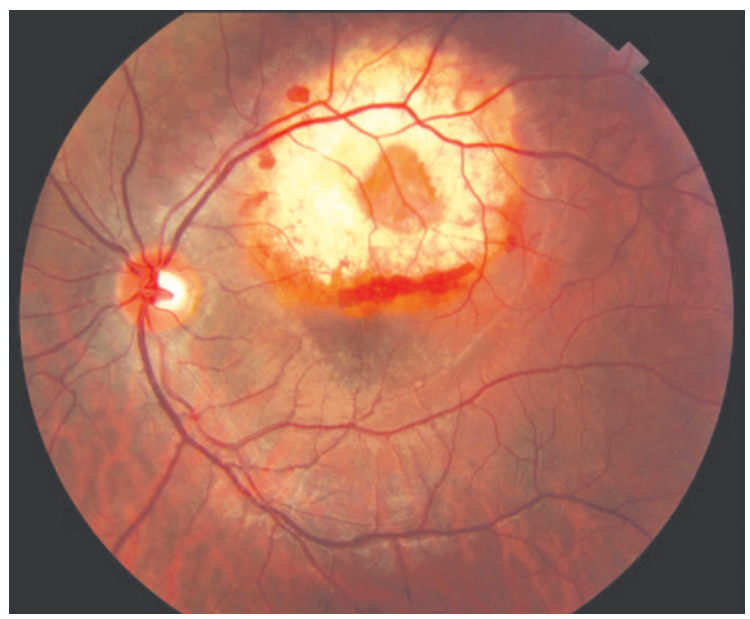

Figure 1. Color photograph of a choroidal osteoma with associated choroidal neovascularization. The neovascularization lies in the center of the lesion, and a subretinal hemorrhage is nasally and inferiorly noted.

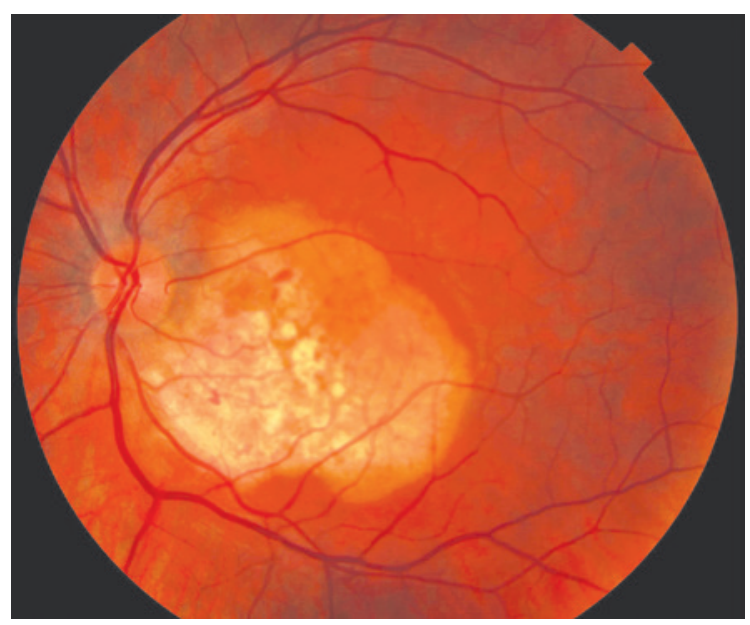

Figure 2. Color photograph of a choroidal osteoma with associated choroidal neovascularization. The neovascularization is located on the papillomacular bundle, and small spots of subretinal hemorrhage are noticed around it.
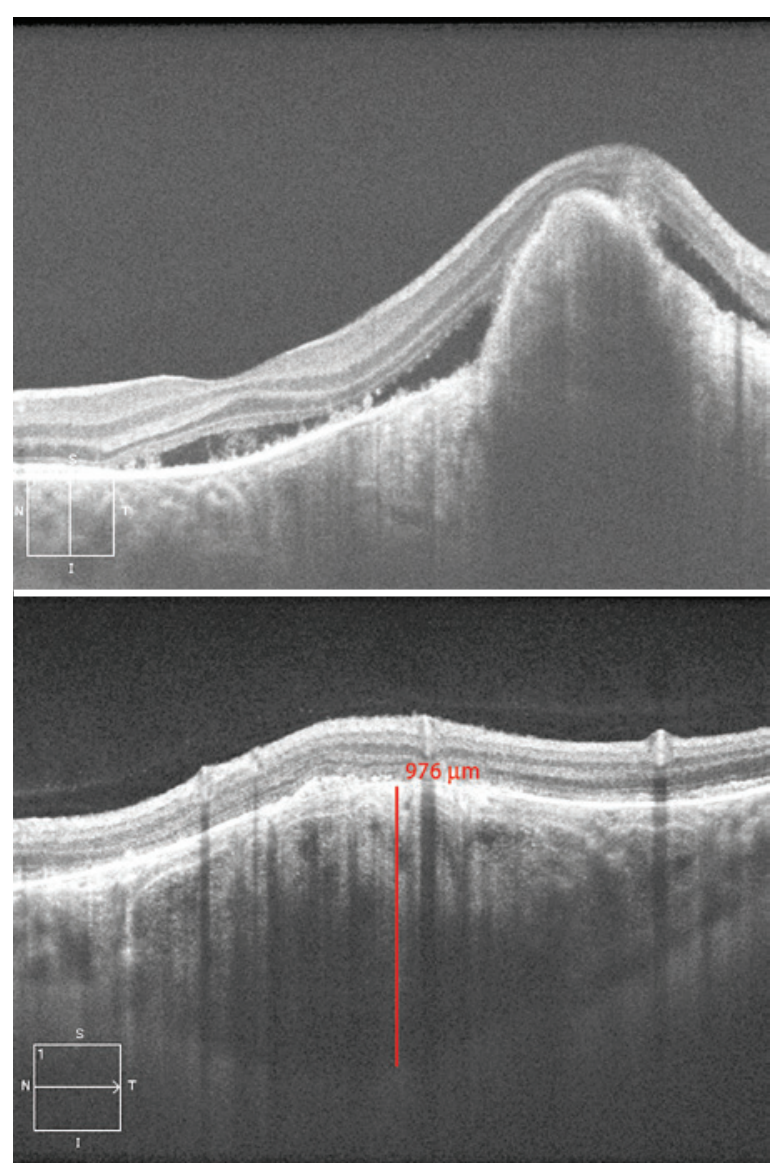

Figure 3. Enhanced depth imaging optical coherence tomography (EDI-OCT) images from case 1 affected by a choroidal osteoma with neovascular membrane. A multilayer configuration with a discrete sponge-like pattern was observed. The sclerochoroidal junction was detected, but we could not see it in all parts under the tumor because CNV had a fibrotic component that obscured the posterior part of the membrane. The choroidal thickness was 976 micra at the parafoveal area.

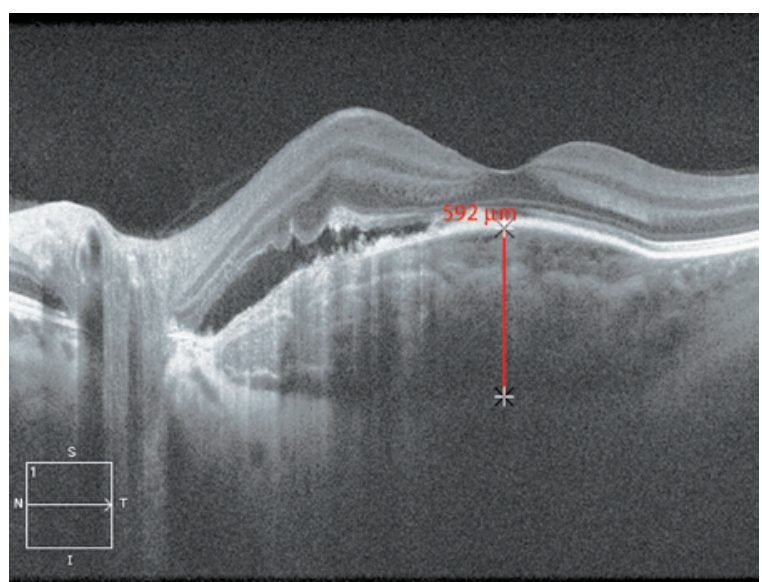

Figure 4. EDI-OCT images from case 2 affected by a choroidal osteoma with neovascular membrane. A multilayer configuration with a discrete sponge-like pattern was observed. The sclerochoroidal junction was detected in all parts of the tumor revealing a typical intrinsic transparency. The choroidal thickness was 592 micra at the foveal area. 
grity of the photoreceptor layer in calcified areas and disruption in decalcified areas, similar to what was previously reported in $2007^{(9)}$. The choriocapillaris was thinned in both cases. Medium-caliber vessels (Sattler's layer) showed thinning and no visibility in both cases, whereas large-caliber vessels (Haller's layer) appeared as thinned rims of vessels between the tumor and sclerochoroidal junction, as was recently reported ${ }^{(6)}$. This finding is supported by histopathologic evidence from previous reports ${ }^{(10)}$

EDI-OCT of the osteoma revealed a typical reflectivity pattern in both cases with the presence of hyperreflective horizontal lamellar lines, which were described in other reports ${ }^{(5,6)}$. These characteristics could represent varying degrees of calcification within the tumor because of the different phases of bone tissue formation. We noticed multiple hyperreflective dots scattered in the hyporeflective matrix creating a sponge-like appearance as previously reported ${ }^{(6)}$, but they were very subtle, especially under the CNV area. The sclerochoroidal junction was detected in both cases; however, in case 1, we were unable to detect it in all parts under the tumor because CNV had a fibrotic component that produced shadowing posterior to the membrane. The choroidal thickness was 976 micra in case 1 and 592 micra in case 2.

The features described in the two cases mentioned above, compression of the choriocapillaris and disorganization of the medium and large vessel layers, are consistent with those of previous reports ${ }^{(4-6)}$. We noticed the sponge-like pattern previously reported ${ }^{(4-6)}$, but it was subtle. Both lesions had multiple intralesional layers and a typical intrinsic transparency with visibility of the sclerochoroidal junction, except in the area where CNV had a fibrotic component.
In agreement with the findings of other authors ${ }^{(4)}$, we showed that EDI-OCT is a new and important tool in the differential diagnoses of amelanotic lesions. Our findings highlight how EDI-OCT may be helpful in studying CNVs secondary to choroidal osteomas.

\section{REFERENCES}

1. Torres VL, Brugnoni N, Kaiser PK, Singh AD. Optical coherence tomography enhanced depth imaging of choroidal tumors. Am J Ophthalmol. 2011;151(4):586-93 e.2.

2. Linsenmeier RA, Padnick-Silver L. Metabolic dependence of photoreceptors on the choroid in the normal and retina. Invest Opthalmol Vis Sci. 2000;41(10):3117-23.

3. Spaide RF, Koizumi H, Pozonni MC. Enhanced depth imaging spectral-domain optical coherence tomography. Am J Ophthalmol. 2008;146(4):496-500.

4 .Shields CL, Pellegrini M, Ferenczy SR, Shields JA. Enhanced depth imaging optical coherence tomography of intraocular tumors. from placid to seasick to rock and rolling topography- the 2013 Francesco Orzalesi Lecture. Retina. 2014;34(8):1495-512.

5. Shields CL, Arepalli S, Atalayl HT, Ferenczy SR, Fulco E, Shields JA. Choroidal osteoma shows bone lamella and vascular channels on enhanced depth imaging optical coherence tomography in 15 eyes. Retina. 2015;35(4):750-7.

6. Pellegrini M, Invernizzi A, Giani A, Staurenghi G. Enhanced depth imaging optical coherence tomography features of choroidal osteoma. Retina. 2014:34(5):958-63.

7. Aylward GW, Chang TS, Pautler SE, Gass JD. A long term follow-up of choroidal osteoma. Arch Opthalmol. 1998;116(10):1337-41.

8. Shields $\mathrm{CL}$, Sun $\mathrm{H}$, Demerci $\mathrm{H}$, Shields JA. Factors predictive of tumor growth, tumor decalcification, choroidal neovascularization, and visual outcome in 74 eyes with choroidal osteoma. Arch Ophthalmol. 2005;123(12):1658-66.

9. Shields CL, Perez B, Materin MA, Mehta S, Shields JA. Optical coherence tomography of choroidal osteoma in 22 cases: evidence for photoreceptor atrophy over the decalcified portion of the tumor. Ophthalmology. 2007;114(12):e53-8.

10. Foster BS, Fernandez-Suntay JP, Dryja TP, Jakobiec FA, D' Amico DJ. Clinicopathologic reports, case reports, and small case series: surgical removal and histopathologic findings of a subfoveal neovascular membrane associated with choroidal osteoma. Arch Ophthalmol. 2003:121(2):273-6.

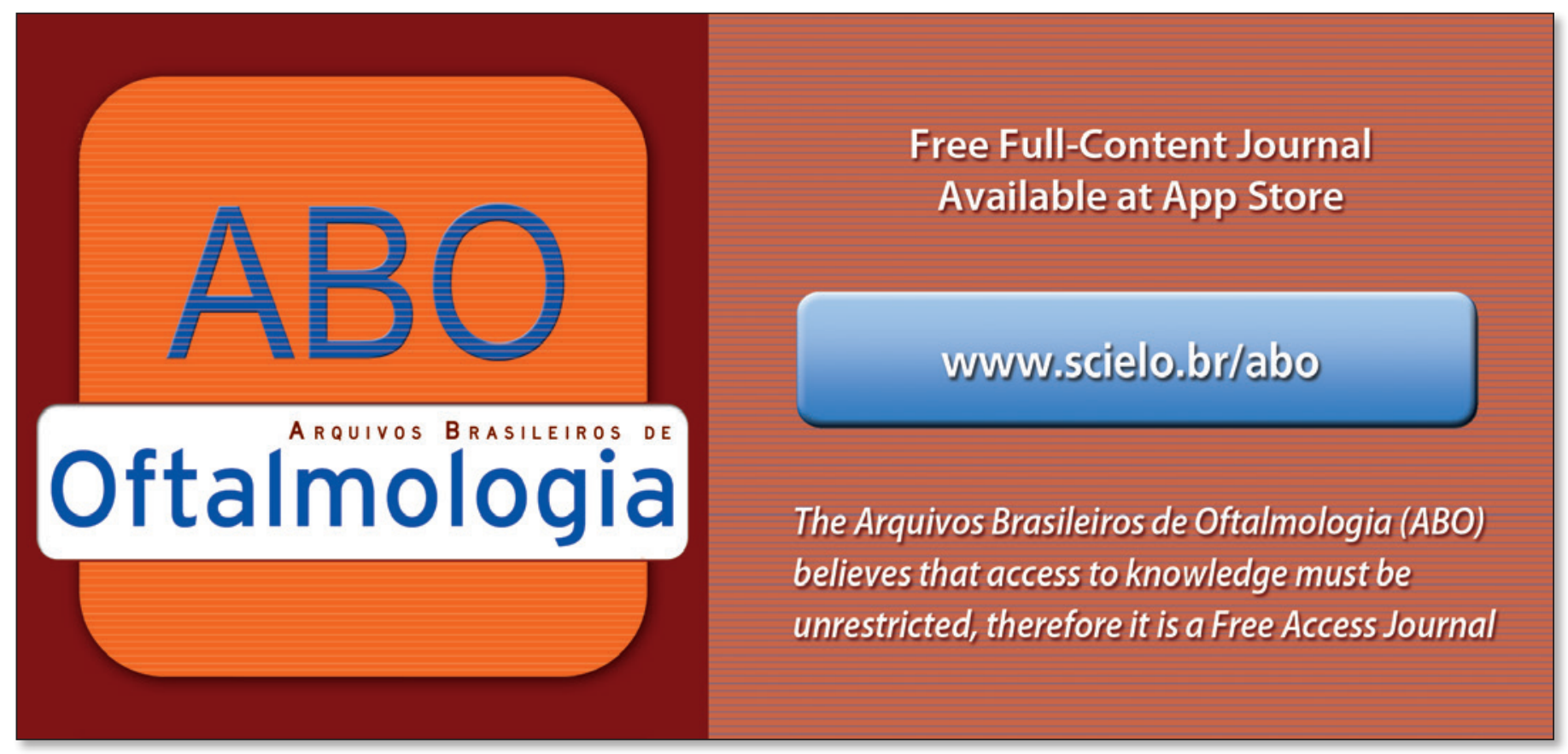

